\title{
CHANGE OF NAME BY A PSYCHOTIC PATIENT: IS IT MANIFESTATION OF A PSYCHOPATHOLOGY MISSED UNTIL NOW?
}

\author{
Usama Bin Zubair, Eugene G Breen*, Muhammad Shahbaz Shoaib**, Hamza Bin Zubair*** \\ Liasion Psychiatry Conolly Hospital, Dublin Ireland, ${ }^{*}$ Mater University Hospital Ireland, ${ }^{* *}$ Combined Military Hospital Malir/National University of Medical \\ Sciences (NUMS) Pakistan, ${ }^{\star * *}$ Holy Family Hospital, Rawalpindi Pakistan
}

\begin{abstract}
We present a case of a 24-year-old woman who changed her name 3 years after the diagnosis of schizophrenia. She had recurrent thoughts of changing her name for over a year and described her feelings as terrible as if captured in a dark room. She also had obsessional thoughts regarding God talking to her, body image and size. Low self-esteem was a constant feature. The psychopathology of her name changing seemed to be meshed between normal desire, obsessional fixation, overvalued ideas of its benefit, and psychotic thought processes.
\end{abstract}

Keywords: Change of name, Psychopathology, Psychosis.

How to Cite This Article: Zubair UB, Breen EG, Shoaib MS, Zubair HB. Change of Name by a Psychotic Patient: Is it Manifestation of a Psychopathology Missed Until Now. Pak Armed Forces Med J 2021; 71(6): 2259-2261. Doi: https://doi.org/10.51253/pafmj.v71i6.6973

This is an Open Access article distributed under the terms of the Creative Commons Attribution License (https://creativecommons.org/licenses/by-nc/4.0/), which permits unrestricted use, distribution, and reproduction in any medium, provided the original work is properly cited.

\section{INTRODUCTION}

A person's name imparts a unique identity and it usually stays with the person throughout life and after death. Many people change their names for various reasons. ${ }^{1,2}$ "What's in a name?" you might ask, and Romeo and Juliette found out that there is quite a bittheir lives were shackled by their family names. Name changing occurs in all cultures around the world in one form or another. A study done in the UK discussed the social aspects behind name changing. It concluded that favourableness toward nationality, satisfaction with one's experience, the relative perception of personal and national evaluation and change in self-esteem are some of the reasons behind the desire to change one's name. ${ }^{3}$ Martin et al, found that up to one-fifth of psychiatric offender patients had changed their names at least once. Offenders with psychosis, more than other patients, gave idiosyncratic reasons for changing their name and the names they selected were characterized by being relatively famous names or names that carried symbolic significance. ${ }^{4}$ Authors noted that the reasons given for name changes by patients in their sample with a diagnosis of schizophrenia sounded as if they might be delusional "It was something mysterious, sinister. Sinister, mysterious name. ${ }^{4}$

\section{CASE REPORT}

A 24-year-old lady diagnosed with schizophrenia three years ago, gave informed consent to share her

Correspondence: Dr Muhammad Shahbz Shoaib, Department of Medicine, Combined Military Hospital Malir-Pakistan

Received: 29 Jun 2021; revision received: 04 Oct 2021; accepted: 05 Oct 2021 case. Initially, she was diagnosed with delusional disorder and then schizoaffective but her final diagnosis was schizophrenia. One year ago, she changed her name by deed poll. All her official and medical documents were altered to reflect her new name. At the interview, she was at her best baseline with no psychotic symptoms but repeated obsessional thoughts. She discussed having repeated thoughts about changing her name prior to doing it. She described how God spoke to her regularly in her head. She described being very unhappy with her previous name saying people couldn't pronounce it. She denied any meaning or belief associated with her previous name. She was very happy and content after changing and felt it might help her get a job. She denied any delusional thinking about her new name. She had thought about it for over a year and she expressed content with having done it.

She said her parents and sister were supportive and there were no family or societal issues as a result. The treating psychiatrist supported her change. She changed it three years after the diagnosis of schizophrenia. She had repeated thoughts that her first name was very difficult and people around her didn't like it. She felt "trapped in a dark room with that name." After changing the name, she felt relaxed and as if she had come out of that dark room. She is now thinking of changing her family name and date of birth.

Regarding her past psychiatric history, she started feeling depressed and detached four years ago with a belief that people were watching her and staring at her. She believed people were following her. In addition, 
she had repeated thoughts of distorted body image and size that lead to low self-esteem and social anxiety. She had repeated thoughts regarding God controlling her thoughts and actions. She regarded these thoughts a problematic and they were sometimes comforting but mostly coupled with a lot of anxiety. She had a flat affect. She regarded the thoughts in her mind sometimes as voices that would tell her what to do, or be a source of support and consolation for her.

She never endorsed voices from outside her head and always described her symptoms as a voice inside her head "maybe my voice or thoughts." Her attention, concentration, memory and cognition were intact.

She had partial insight into her symptoms at the time of presentation. She presented with self-harm (overdose) five times secondary to low mood due to her thoughts and perplexity. She felt very much alone in the world with her bothersome thoughts and concerns with self-image.

There was no family history of any psychiatric disease or any name change. She had normal birth and development and no significant childhood history. She denied the use of alcohol and illicit drugs and had no forensic history.

She had polycystic ovary syndrome diagnosed and was on no medication for it. She was significantly overweight. She had a detailed psychological assessment regarding her affective, psychotic and obsessional symptoms. Her clinical outcome in routine evaluation score (CORE) was moderate to severe. She seemed constantly disturbed by unwanted thoughts. Personality assessment inquiry (PAI) was highly consistent with the diagnosis of schizophrenia. The resentment facet of the paranoia subscale was elevated.

She was managed on a bio-psycho-social model. She was stabilized on Quetiapine $350 \mathrm{mg}$ Nocte, Sertraline $200 \mathrm{mg}$ and Paliperidone depot $525 \mathrm{mg}$ every three months. The occupational therapist and psychology services were also involved. At present, she is at her best baseline on the above-mentioned medications.

The possible contributors to the name change may be linked to delusional process (ideas of reference and persecution); organic illness (PCOS) leading to obesity which lead to obsessional thoughts regarding weight and body image causing low self-esteem and social anxiety; or some overvalued idea that a name change and change of date birth might in some way get rid of her illness and help her start a new life.

\section{DISCUSSION}

The act of name-changing may be in the context of forming connections, blending in with a new environment, marking a valued affiliation or being reborn into a new religion. Sometimes, however, changing one's name can serve as a separation. It can be a way to hide one's former identity, to repudiate one's ancestry. ${ }^{4}$ These are the usual reasons in the population and people with psychiatric illnesses may also have these reasons. Our patients' reason for a name change may be part of her abnormal perceptions and interpretation of reality due to delusional thinking.

Mental illness may alter the personality of the individual, their perception of reality, and their concept of self and others. Impaired cognition and thought disorder may manifest as delusions. ${ }^{5}$ In the light of these effects one is not surprised to see patients with mental illness changing their names-possibly not so much from a social motivation but secondary to their psychopathology. Each psychiatric illness has specific psychopathology which could contribute to name changing. In this case, the altered concept of self and obsessional thinking related to it may have compelled her to change her name.

In a 12-year retrospective study of patients attending a psychiatric unit (31\% of whom suffered from schizophrenia), $0.7 \%$ adopted an alias at some stage in their lives. ${ }^{6}$ Forensic populations and transgender people are other populations known to name change. ${ }^{7}$

Name changes for whatever reason or psychopathology raises various issues in society and also in the health care system. Countries, where everything is computerized and runs on the stored data of individuals' names, have many challenges in such situations. 8 Limited data is available regarding name changing among psychotic patients and the psychopathology behind this phenomenon. Further research is warranted to identify the psychopathology behind name change in psychotic patients.

\section{Conflict of Interest: None.}

\section{Authors' Contribution}

UBZ: Conceived idea, Set methodology, EGB: Manuscript writing, Statistical analysis, MSS: Manuscript writing, HBZ: Proof Reading.

\section{REFERENCES}

1. Restart A, Jin H, Breslow A, Reisner SL, Mimiaga M, Cahill S, et al. Legal gender marker and name change is associated with a lower negative emotional response to gender-based mistreatment and improve mental health outcomes among trans populations. SSM Popul Health 2020; 11(1): 100595. 


\section{Psychotic Patient Name Change}

2. Russell ST, Pollitt AM, Li G, Grossman AH. Chosen name use is linked to reduced depressive symptoms, suicidal ideation, and suicidal behavior among transgender youth. J Adolesc Health 2018; 63(4): 503-505.

3. Pilcher J. Names and "Doing Gender": How Forenames and surnames contribute to gender identities, difference, and inequalities. Sex Roles 2017; 77(11): 812-822.

4. Martin RE, Hislop TG, Grams GD, Moravan V, Calam B. Beware of multiple names in database linkage research: prevalence of aliases in the female prison population. Br Med J 2005; 331(7512): 335-336.
5. Malla A, Joober R,. Mental illness is like any other medical illness: a critical examination of the statement and its impact on patient care and society. J Psych Neurosci 2015; 40(3): 147-150.

6. Meagher DJ, Collins AG. The use of aliases by psychiatric pati-ents. Psychopathol 1997; 30(3): 324-327.

7. Hill BJ, Crosby R, Bouris A, Brown R, Bak T. Exploring transgender legal name change as a potential structural intervention for mitigating social determinants of health among transgender women of colour. Sex Res Social Policy 2018; 15(1): 25-33.

8. Lichtner V, Wilson S, Galliers JR. The challenging nature of patient identifiers: an ethnographic study of patient identification at a London walk-in centre. Health Inform J 2008; 14(2): 141-50. 